\title{
Recurrence of pituitary adenomas after transcranial operation
}

\author{
LINDSAY SYMON, VALENTINE LOGUE, ${ }^{*}$ SURESWAR MOHANTY† \\ From the Gough Cooper Department of Neurological Surgery, Institute of Neurology and National Hospital, \\ London, $U K$
}

SUMMARY A series of 289 pituitary adenomas operated upon transcranially have been assessed for the frequency of recurrence. Ten patients died in the postoperative period, and nine patients have been lost to follow up. Follow up data is therefore available in a series of 270 cases for a period extending up to 30 years after the initial operation. There have been 13 histologically verified recurrences $(4.8 \%)$, and a further six cases are known from CT scan or air study evidence to have residual or recurrent tumour which has not necessitated re-exploration. The total recurrence or residual tumour rate could therefore be regarded as $7.4 \%$.

The large majority $(77 \%)$ of recurrences have been within 10 years of the first operation, and the rest between 10 and 20 years. Histologically, all were chromophobe adenomas, and the average age of their initial presentation was lower than the peak incidence of pituitary adenoma as a whole. Two patients showed frank malignant change in the second biopsy. In recurrent tumours, most had had only subtotal excision with some macroscopic evidence of invasion or degeneration, such as cystic change, haemorrhage or necrosis. Microscopic evidence of aggressive growth and capsular invasion by tumour cells also was relatively frequent. Postoperative radiotherapy decreased and delayed recurrence, although the vast majority of cases in the series received radiotherapy. Surgery for recurrence appeared an effective method of treatment, and no patient died following repeated operation. Initial transcranial excision in more recent years using the operating microscope followed by uniform radiotherapy, appears to have considerably reduced the already small recurrence rate of pituitary adenoma.

Despite apparently adequate macroscopic excision and radiotherapy, a definite, if small, recurrence rate of pituitary adenomas remains. The five year recurrence of large series following transcranial operation varies from 7 to $35 \% .{ }^{1-10}$ When transcranial surgery was combined with radiation therapy, the five year recurrence rate was $13 \%$ in contrast to $42.5 \%$ with surgery alone (Cushing's series). Visual disturbance is the commonest manifestation of recurrence. ${ }^{8}$ Postoperative arachnoid cyst, ${ }^{11}$ empty sella syndrome and radiation effects ${ }^{12}$ may be confused with tumour recurrence. German and Flanigan $^{13}$

\footnotetext{
*Emeritus Professor of Neurological Surgery, Institute of Neurology.

$\dagger$ This study was carried out during the tenure of a Commonwealth Fellowship by Dr Mohanty.

Address for reprint requests: Prof Lindsay Symon, The National Hospital, Queen Sq., London WC1N 3BG, UK.

Received 17 March 1982. Accepted 24 April 1982
}

observed that adenomas vary in their growth potential and there are reported examples of patients with many years of symptomatic freedom following minimal tumour removal and others who suffered rapid tumour recurrence after "ideal" treatment. The majority of recurrences occur within three to five years after surgery. ${ }^{12810}$ Stern and Batzdorf reported the least recurrence in radical removal (with or without chemical corrosion of the evacuated sella), and excision of suprasellartissue. All capsules were removed to the plane of the diaphragma sellae with intracapsular currettage of all grossly visible and palpable tumour. Partial excision showed a higher recurrence rate. McCallum $^{10}$ had 12 recurrences in 44 chromophobe adenomas in whom he had performed only intracapsular removal with the capsule in most cases left in place. Guiot ${ }^{14}$ has stated that recurrence is due to residual tumour fragments left by the surgeon, although more likely to occur if the tumour has a greater cell density or some abnormalities in cellular morphology. He has 
further suggested that recurrence develops sooner and more seriously in young patients. Pituitary adenomas are known to grow in response to endocrine disturbances such as following adrenalectomy in Cushing's syndrome. ${ }^{1516}$ Recurrent adenomas have been reported to have a very high mortality. ${ }^{17-19}$ The present retrospective study was undertaken to assess the factors responsible for recurrence after transcranial surgery, by a long follow up of a series of cases treated in a single centre by two surgeons (VL and LS). We have also reviewed the pattern of recurrence, and the role of re-operation in this group.

\section{Patients and methods}

The series comprised 289 patients with pituitary tumour treated during the period 1948 to 1979 at the National Hospital, Queen Square, and Maida Vale Hospital, London, by the first two authors. These cases had 304 transcranial operations, 13 cases having 15 operations for recurrence. Histological verification was available in each case. All 13 presented with delayed visual failure after initial operation. Other causes of delayed visual failure following the first operation are shown in table 1 . One patient who had a recurrence with an intrasellar blood cyst and seven patients who had some evidence of recurrence on air study or CT scan were excluded from the present study, since histological verification of recurrence was not available.

Table 1 Causes of delayed visual failure following transcranial operation and radiotherapy for pituitary adenoma

Total number of verified pituitary adenoma

Number of post operative deaths

Number of cases with delayed visual failure

Recurrence of adenoma

Histologically verified

On air study or CT scan

Recurrence as a blood cyst

Empty sella syndrome

Radiation effect

Hydrocephalus

The follow up period extended up to $\mathbf{3 0}$ years after initial surgery (table 2 ). There were ten postoperative deaths in 289 cases (3.4\%), almost all of whom had giant or large invasive lesions. ${ }^{20}$ Nine cases have been lost to protracted follow up, all from overseas. Complete follow up therefore consists of 270 cases. A complete follow up consisted of collection of information regularly from the time of the first operation regarding general well-being, visual status, endocrine status, re-operation for pituitary tumour if the patients were surviving, or cause of death if deceased. A total of 34 cases were operated between 1948 and 1959 of which 30 had complete follow up for at least 20 years. Between 1960 and 1969, 80 cases were operated of which 70 had complete follow up for at least ten years. During 1970 and 1979,175 cases were operated, of which 120 had
Table 2 Length of post operative follow up

\begin{tabular}{lrccll}
\hline Years & No of cases & Follow up available & No of recurrences \\
\cline { 3 - 5 } & & Complete & $\begin{array}{c}\text { Incomplete } \\
\text { (op death) }\end{array}$ \\
\hline $1948-59$ & 34 & 30 & 4 & 7 \\
$1960-69$ & 80 & 70 & 10 & 6 \\
$1970-79$ & 175 & 170 & 5 & 0 \\
Total & 289 & 270 & 19 & $(10)$ \\
\hline
\end{tabular}

follow up for at least five years. Nine cases had incomplete follow up, mostly due to loss of contact in a foreign country. The large majority of this group had at least five years follow up, during which maximum recurrence is known to occur. Information regarding 47 deaths are available during this follow up study. These include four deaths that had occurred among 13 recurrent adenomas, and the rest due to natural or unrelated causes.

\section{Results}

Histologically verified recurrence was found in 13 cases of the 270 . The symptom of recurrence was invariably delayed visual failure. Half the recurrent cases showed increase in headache and two cases ophthalmoplegia. There were seven females and six males, with a mean age of 37.7 years. Nine of the recurrent cases were aged below 40 years. The mean interval of visual symptoms at recurrence was $7 \cdot 1$ years. Of the recurrences, ten, that is $77 \%$, occurred within the first ten years following initial surgery. A further three $(23 \%)$ occurred after ten years, the latest being at 15 years.

The thirteen patients who had verified recurrences are shown in table 3. Two patients had a total of six operations, that is, two recurrences each. Three patients had had initial radical removal and 10 patients had partial removal of varying degrees (that is, Class 2-4 of operative procedures described by Stern $\left.e t \mathrm{al}^{7}\right)$. Postoperative radiotherapy after the first operation was not given to six $(46 \%)$ of the cases which subsequently recurred in contrast to only $27(10 \%)$ of cases which did not receive radiotherapy among the cases as a whole. However, 12 of these 13 cases had postoperative radiotherapy after the second operation. A portion of this series operated upon since 1968 , largely with the help of operating microscope and with invariable postoperative radiation, has been reported earlier. ${ }^{29}$

All the cases which recurred were chromophobe adenomas at the original biopsy, but two of them, cases 6 and 11, showed malignant change at the first recurrence. No case showed metastasis, though one case (case 6) showed chromophobe adenoma cells in the CSF. All cases save one showed clinical hypopituitarism, the exception being a case of $\mathrm{Nel}$ son's syndrome. Pertinent operative and histological 
Table 3 Verified recurrent pituitary adenomas associated with visual failure

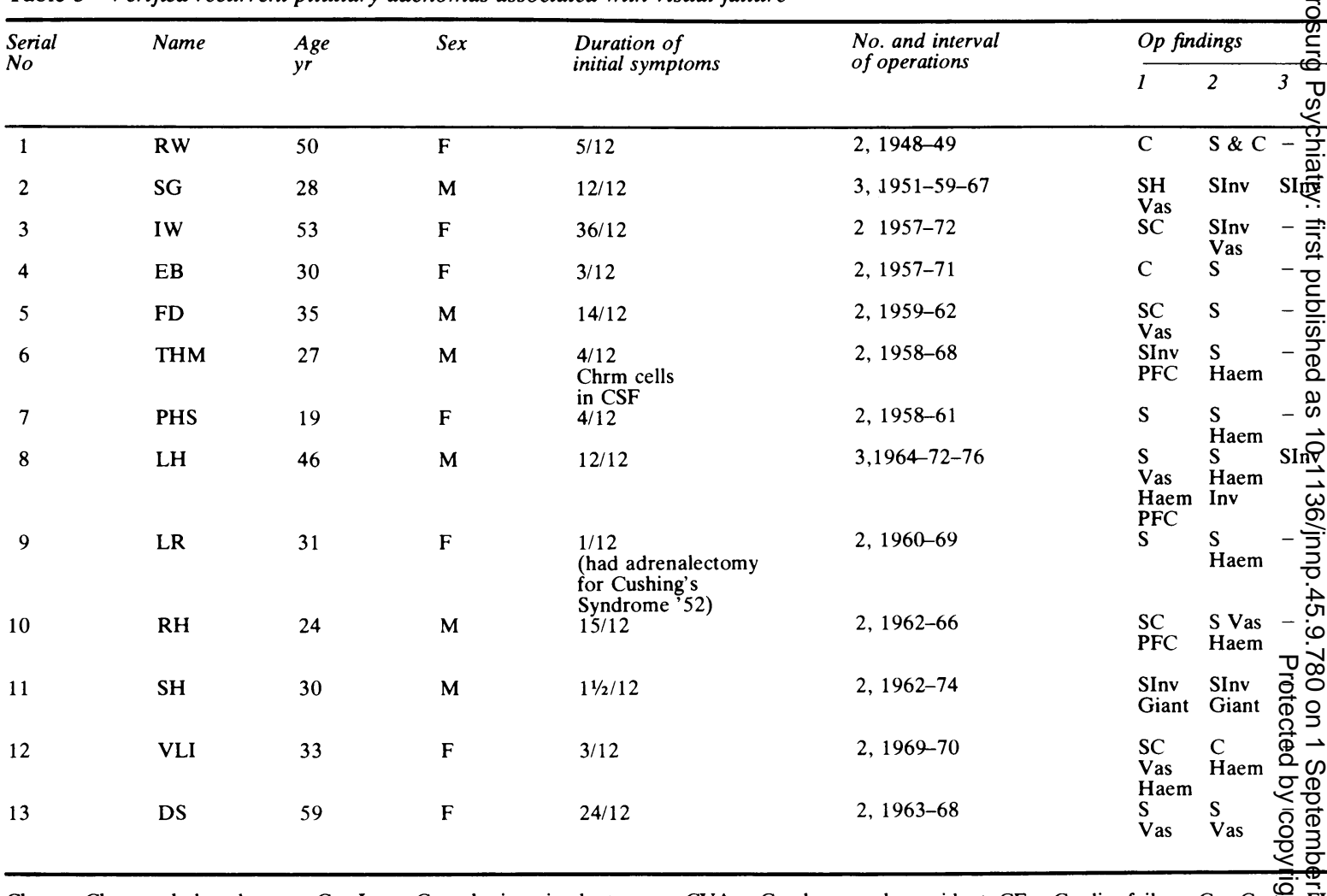

Chrm = Chromophobe adenoma; Cap Inv = Capsular invasion by tumour; CVA = Cerebrovascular accident; $\mathrm{CF}=\mathrm{Cardiac}$ failure; $\mathrm{C}=\mathrm{Cys} \mathbf{C}, \mathrm{E}$ = Follow up; Inv = Invasive; Radiotherapy "-" = not given; Radiotherapy " +" = given; Haem = Haemorrhage; Malig = Malignant; PF( Prefixed chiasm; $\mathbf{P}=$ Partial; $\mathrm{R}=$ Radical; Pleo = Pleomorphic; Vas = Vascular; $\mathbf{S}=\mathrm{Solid}$.

findings in 28 operations (including the primary operation) upon 13 recurrent cases is shown in table 4. Macroscopic degenerative changes were noted in 14 cases $(50 \%)$, increased vascularity in eight $(27 \%)$ and invasive features in seven $(25 \%)$. Histological evidence of capsular invasion by tumour cells was seen in six cases $(23 \%)$, but since capsule was not available in all histological specimens, this incidence is quite inexact. Microscopic haemorrhage was noted in four specimens (14\%).

Table 4 Operative and histological findings

Total number of verified recurrent adenomas
Radiation not given after first operation
Total number of operations performed
Partial excision
Macroscopic degenerative changes (cystic, necrotic
haemorrhagice)
Invasive
Vascular
Capsular invasion
Pleomorphism
Haemorrhage
Malignant change

Re-operation in this group of 13 cases carried no mortality. The mean survival period after the second operation was 11.5 years. After the second operation, seven of the 13 patients showed significant improvement in vision. All recurrent tumours that were operated on before 1970, were operated without the help of the operating microscope. The ten recurrences of the early portion of the series had what we would now regard as partial excision, and nearly half of them did not receive postoperative radiotherapy.

\section{Discussion}

Pituitary adenomas are usually benign, slowgrowing tumours and malignant change is extremely rare. $^{21}$ When they extend beyond their capsular limits into adjacent structures by local spread, they are termed malignant ${ }^{22}$ or invasive. ${ }^{53}$ The term carcinoma is generally reserved for those cases having distant metastasis, either blood borne or spread along CSF pathways. ${ }^{24} 25$ Of the thirteen recurrent 


\begin{tabular}{|c|c|c|c|c|c|c|c|c|}
\hline \multicolumn{3}{|c|}{$\begin{array}{l}\text { Extent of } \\
\text { excision }\end{array}$} & \multicolumn{2}{|c|}{ Post-op } & \multicolumn{3}{|c|}{ Histology } & \multirow{2}{*}{$\begin{array}{l}\text { Follow-up } \\
\text { since first } \\
\text { operation }\end{array}$} \\
\hline 1 & 2 & 3 & 1 & 2 & 1 & 2 & 3 & \\
\hline $\mathbf{P}$ & $\mathbf{R}$ & - & - & + & Chrm & \multicolumn{2}{|l|}{ Chrm } & \multirow{3}{*}{$\begin{array}{l}\text { Lived } 29 \mathrm{yr} \\
\text { died in sleep } \\
\text { Lived } 24 \mathrm{yr} \\
\text { Died CVA } \\
\text { Alive } 23 \mathrm{yr}\end{array}$} \\
\hline $\mathbf{P}$ & $\mathbf{P}$ & $\mathbf{P}$ & + & + & Chrm & Chrm & Chrm & \\
\hline $\mathbf{R}$ & $\mathbf{P}$ & - & - & + & Chrm & Chrm & & \\
\hline $\mathbf{R}$ & $\mathbf{P}$ & - & - & + & Chrm & Chrm & & \multirow{2}{*}{$\begin{array}{l}\text { Lived } 13 \text { yr } \\
\text { Died CF } \\
\text { Alive } 19 \text { yr }\end{array}$} \\
\hline $\mathbf{P}$ & $\mathbf{P}$ & - & + & + & Chrm & $\begin{array}{l}\text { Chrm } \\
\text { Pleo }\end{array}$ & & \\
\hline $\mathbf{P}$ & $\mathbf{P}$ & - & + & + & $\begin{array}{l}\text { Chrm } \\
\text { Nec }\end{array}$ & $\begin{array}{l}\text { Chrm } \\
\text { Pleo . } \\
\text { Malig }\end{array}$ & & $\begin{array}{l}\text { Lived } 17 \mathrm{yr} \\
\text { Lost to } \mathrm{F} / \mathrm{U}\end{array}$ \\
\hline $\mathbf{P}$ & $\mathbf{P}$ & - & - & + & \multirow{2}{*}{$\begin{array}{l}\text { Chrm } \\
\text { Pleo } \\
\text { Chrm } \\
\text { Haem }\end{array}$} & $\begin{array}{l}\text { Chrm } \\
\text { Pleo }\end{array}$ & & \multirow{2}{*}{$\begin{array}{l}\text { Lived } 18 \mathrm{yr} \\
\text { Lost to F/U } \\
\text { Lived } 17 \mathrm{yr} \\
\text { Died Rec }\end{array}$} \\
\hline $\mathbf{P}$ & $\mathbf{P}$ & $\mathbf{P}$ & + & - & & $\begin{array}{l}\text { Chrom } \\
\text { Haem }\end{array}$ & $\begin{array}{l}\text { Chrm } \\
\text { Haem }\end{array}$ & \\
\hline $\mathbf{P}$ & $\mathbf{P}$ & - & - & + & Chrm & $\begin{array}{l}\text { Chrm } \\
\text { Haem }\end{array}$ & & Alive 21 yr \\
\hline $\mathbf{P}$ & $\mathbf{P}$ & - & - & + & \multirow{3}{*}{$\begin{array}{l}\text { Chrm } \\
\text { Cap } \\
\text { Inv } \\
\text { Chrm } \\
\text { Pleo } \\
\text { Inv } \\
\text { Chrm } \\
\text { Haem }\end{array}$} & \multirow{3}{*}{\multicolumn{2}{|c|}{$\begin{array}{l}\text { Chrm } \\
\text { Pleo } \\
\text { Cap Inv } \\
\text { Chrm } \\
\text { Cap Inv } \\
\text { Malig } \\
\text { Mixed } \\
\text { cell }\end{array}$}} & Alive $18 \mathrm{yr}$ \\
\hline $\mathbf{P}$ & $\mathbf{P}$ & - & + & + & & & & $\begin{array}{l}\text { Lived } 12 \text { yr } \\
\text { Dead Rec }\end{array}$ \\
\hline $\mathbf{P}$ & $\mathbf{P}$ & - & + & + & & & & Alive 11 yr \\
\hline $\mathbf{P}$ & $\mathbf{P}$ & - & + & + & $\begin{array}{l}\text { Chrm } \\
\text { Cap } \\
\text { Inv }\end{array}$ & \multicolumn{2}{|l|}{$\begin{array}{l}\text { Chrm } \\
\text { Cap } \\
\text { Inv }\end{array}$} & $\begin{array}{l}\text { Alive } 17 \mathrm{yr} \\
\text { 3rd rec on } \\
\text { CT scan }\end{array}$ \\
\hline
\end{tabular}

pituitary adenomas studied by us, none had distant metastases, although in one case, chromophobe adenoma cells were found in CSF. Histologically, only two cases showed malignant change at the second biopsy. However, pleomorphism and capsular invasion by tumour cells were frequently observed.

Most of the recurrences have been reported to occur within five years following treatment ${ }^{121819}$ and only rarely are they known to occur later. In Cushing's series, ${ }^{2}$ the latest known recurrence occurred eight years after surgery and in another report $^{19}$ eight of the 24 recurrences occurred after five years (at six, eight, ten, eleven, twelve and thirteen years). In the present series, three cases recurred after ten years, the latest one being 15 years after initial operation. There is no mention of recurrence after 15 years in published literature.

Factors which may contribute to local recurrence are surviving fragments of the tumour left by the surgeon, capsular invasion, ${ }^{14}$ aggressive growth potential $^{13}$ or morphological changes in the adenoma cells. ${ }^{14} 25$ It is possible, however, that large, giant or invasive adenomas might have aggressive growth spurts as in these tumours necrosis, cystic degeneration and haemorrhage are common features. ${ }^{2526}$ Our observation reveals that the vast majority $(89 \%)$ of recurrent adenomas had only partial excision. The presence of a pre-fixed chiasm, unusual vascularity or large or giant adenomas with involvement of adjacent vital structures, and the cavernous sinus, were important factors limiting a radical excision, particularly in the pre-microscope era. On the other hand, peculiar biological behaviour of recurrent adenomas were the higher incidence of degenerative changes and aggressive features in what is generally a benign, slow-growing tumour.

Growth stimulation is known to occur in the adenohypophyseal cells following adrenalectomy ${ }^{15} 16$ implicating a hormonal factor in the growth of adenohypophyseal tumour. One of the recent adenomas in our series had Nelson's syndrome, but the others clinically and endocrinologically showed hypopituitarism. Host-tumour relationship and 
immunological aspects of pituitary adenomas may reveal further factors in recurrence, but so far definite information on such considerations is lacking.

Martin $^{5}$ and Guiot ${ }^{14}$ have stated that invasive pituitary adenomas are curable by radiation. Our observation agrees very well with earlier reports of decrease or delay of recurrence following radiotherapy. ${ }^{1014}$ The inhibition of further tumour growth and subsequent elimination of invasive properties may be better accomplished by alpha particles or the proton beam. ${ }^{21}$ The location of $x$-ray ports and dosimetry can be more accurate with CT guidance. CT has been helpful for early detection of recurrence before visual disturbances occur. However, the use of radiation is not without the hazards of radionecrosis and carcinogenesis. There are no documented reports on the therapeutic efficacy of chemotherapy and immunotherapy for recurrent adenomas. ${ }^{21}$ Complete clinical and biochemical remission of a growth hormone producing tumour which was locally invasive has been reported with bromocriptine. ${ }^{28}$

It is interesting to note that despite the high postoperative mortality quoted ${ }^{1819}$ for recurrent adenomas, no operative deaths occurred in this group of 13 cases, having in total 28 operations. Over half the cases had fair to excellent visual recovery, a mean survival period of 11.5 years after re-operation, and a good quality of life. Irrespective of the approach, whether transphenoidal or transcranial, total excision of an invasive adenoma may not be feasible. The former approach has been recently popular, yet recurrence has been reported $^{1429}$ in a much shorter follow up. However, transcranial operation using the operating microscope during the last decade has facilitated initial radical excision of the adenoma and, combined with postoperative radiotherapy, appears to have reduced recurrence drastically. ${ }^{20}$

\section{References}

' Bakay L. The results of 300 pituitary adenoma operations (Professor Herbert Olivecrona's series). $J$ Neurosurg 1950;7:240-55.

${ }^{2}$ Henderson WR. The Pituitary Adenomata: A follow up study of surgical results in 388 cases (Dr Harvey Cushing's series). Br J Surg 1939;26:809-921.

${ }^{3}$ Krayenbuhl H. Hypophyseal adenomas and craniopharyngiomas. Abstracts and descriptions of scientific program of 2 nd International Congress of Neurological Surgery. Excerpta Med Int Congr Series No 36 1961:E10-E12.

${ }^{4}$ Horrax G, Hare JF, Poppen JL, Hurxthal LM, Younghusband OL. Chromophobe Pituitary Tumours II. Treatment. J Clin Endocrinol 1952;12:631-41.
${ }^{5}$ Martins AM, Hayes GJ, Kempe LG. Invasive pituitary adenomas. J Neurosurg 1964;21:268-76.

${ }^{6}$ Nurnburger JT, Korey SR. Pituitary chromophobe adenomas: neurology, metabolism, therapy. New York. Springer 1953.

${ }^{7}$ Stern EW, Batzdorf U. Intracranial removal of pituitary adenomas. An evaluation of varying degrees of excision from partial to total. J Neurosurg 1970;33:564 73.

${ }^{8}$ Marguth F, Nover A. Morphology und Klinik der hypophysenadenom. Rezidive. Acta Neurochir 1964;11:716-30.

${ }^{9}$ Obrador AS. Adenomas of the pituitary based on a neurosurgical experience of 65 operated patients. Revta. Clin Esp 1961;81:386-440.

${ }_{10}$ MacCullum PJ. Pituitary tumours in the Dunedin Neurosurgical Unit. NZ Med J 1960;59:146-50.

"Echols DH. Experience with surgical treatment in twenty cases of pituitary adenoma. $J$ Neurosurg 1958;15:447-54.

${ }^{12}$ Colby MY Jr, Kearns TP. Radiation therapy of pituitary adenomas associated with visual impairment. Mayo Clin Proc 1962;37:15-24.

${ }^{13}$ German WJ, Flanigan S. Pituitary adenomas: a follow up study of the Cushing Series. Clin Neurosurg 1964;10:72-81.

${ }^{14}$ Guiot G. Consideration on the surgical treatment of pituitary adenomas. In: Treatment of Pituitary Adenomas, Fahlbusch R, Werger K, eds. Stuttgart: Thieme, 1978

${ }^{15}$ Nelson DH, Meakin JW, Thorn GW. ACTH-producing pituitary tumours following adrenalectomy for Cushing's syndrome. Ann Int Med 1960;52:560-9.

${ }^{16}$ Rovit RL, Berry R. Cushing's syndrome and the hypohysis. J Neurosurg 1964;21:170-95.

${ }^{17}$ Ray BS. Surgery of recurrent intracranial tumours. Clin Neurosurg 1964;110:1-30.

${ }^{18}$ Ray BS, Patterson RH. Surgical experience with chromophobe adenomas of the pituitary. J Neurosurg 1971;34:726-9.

${ }^{19}$ Wirth FP, Schwartz HC, Schwetschenanm PR. Pituitary adenoma: Factors in treatment. Clin Neurosurg 1974;21:8-25.

${ }^{20}$ Symon L, Jakubowski J. Transcranial management of pituitary tumours with suprasellar extension. $J$ Neurol Neurosurg Psychiatry 1979;42:123-233.

${ }^{21}$ Clark K. Surgery for the recurrent pituitary adenoma. Clin Neurosurg 1980;27:309-14.

22 Jefferson G. Extrasellar extension of pituitary adenomas. President's Address. Proc Roy Soc Med 1970;33:433-58.

${ }^{23}$ Epstein JA, Epstein BS, Motho L, Zimmerman HA. Carcinoma of the pituitary gland with metastasis to the spinal cord and roots of the cauda equina. $J$ Neurosurg 1964;21:846-53.

${ }^{24}$ Bailey $P$. Tumours of the hypophysis cerebri. In: Penfield W, ed. Cytology and Cellular Pathology of the Nervous System. New York: Hoeber 1932:905-51.

${ }^{25}$ Landolt AM. Ultrastructure of human sellar tumours. Correlation of clinical findings and morphology. Acta Neurochir (Wein) Suppl. 22. 1975.

${ }^{26}$ Symon L, Jakubowski J, Kendall BE. Surgical treatment of giant pituitary adenomas. J Neurol Neurosurg 
Psychiatry 1979;42:973-82.

${ }^{27}$ Mohanty S, Tandon PN, Banerjee AK, Prakash B. Haemorrhage into pituitary adenomas. $J$ Neurol Neurosurg Psychiatry 1977;40:987-91.

${ }^{28}$ Spark RF, Dickstein C, Pallota J. Complete remission of acromegaly with medical treatment. JAMA 1979;241:573-9.

${ }^{29}$ Nicola G. Transphenoidal surgery for pituitary adenomas with extrasellar extension. Prog Neurol Surg 1975;6:142-99. 